\title{
Induced Production of $\alpha$-Tocotrienol by Co-Suppression of Tocopherol Cyclase Gene in Vegetable Crops
}

\author{
1,2 Umaiyal Munusamy, ${ }^{1,3}$ Siti Nor Akmar Abdullah, \\ ${ }^{1,3}$ Maheran Abdul Aziz, ${ }^{4}$ Huzwah Khazaai and ${ }^{1}$ Lai Mun Seong \\ ${ }^{1}$ Department of Agriculture Technology, Faculty of Agriculture, \\ University Putra Malaysia, 43400 UPM Serdang, Selangor Darul Ehsan, Malaysia \\ ${ }^{2}$ Institute of Biological Sciences, Faculty of Science, University of Malaya, 50603 Kuala Lumpur, Malaysia \\ ${ }^{3}$ Laboratory of Plantation Crops, Institute of Tropical Agriculture, \\ ${ }^{4}$ Department of Biomedical Science, Faculty of Medicine and Health Sciences, \\ University Putra Malaysia, 43400 UPM Serdang, Selangor Darul Ehsan, Malaysia
}

Received 2013-09-01; Revised 2013-10-01; Accepted 2013-10-16

\begin{abstract}
This study involves the induced production of $\alpha$-tocotrienol by the co-suppression of tocopherol cyclase gene. The Tocopherol/Tocotrienol Cyclase (TC) is a key enzyme involved in the biosynthesis of $\alpha$ tocotrienol. The partial conserved cDNA of TC gene isolated from the oil palm (Elaeis guineensis) that shared greater than $75 \%$ sequence identity with TC sequences from other plant species was used to silence TC gene expression in Amaranthus sp. and Allium porrum leaves by co-suppression strategies. This was carried out using recombinant vector constructs designated as p4a11 and p4c9 containing TC driven by the maize ubiquitin promoter (Ubi1P) and the oil palm leaf-specific promoter (LHCB), respectively. In the Amaranthus sp. leaves infiltrated with p4a11, the $\alpha$-tocopherol suppression was 85.0, 71.0 and $74.0 \%$ on day three, five and seven, respectively and complete suppression was observed in the leaves infiltrated with p4c9. Whereas, only $11.0,7.0$ and $29.0 \%$ suppression was detected in Allium porrum leaves infiltrated with p4a11 and 45.0, 4.0 and 57.0\% of suppression was observed in Allium porrum infiltrated with $\mathrm{p} 4 \mathrm{c} 9$ on day three, five and seven, respectively. Silencing of TC gene driven by LHCB ( $\mathrm{p} 4 \mathrm{c} 9$ ) causes the reduction of $\alpha$-tocopherol production better than by Ubi1P (p4a11). The results have demonstrated that gene silencing through co-suppression is capable of producing $\alpha$-tocotrienol. However, there is no correlation between the $\alpha$-tocotrienol production and the $\alpha$-tocopherol suppression. It has been suggested that the transgene mediated co-suppression mechanism had triggered the vitamin $\mathrm{E}$ biosynthesis metabolic pathway to shift towards producing $\alpha$-tocotrienol.
\end{abstract}

Keywords:Vitamin E Biosynthetic Pathway, Co-Suppression, Tocopherol Cyclase, $\alpha$-Tocopherol, $\alpha$ Tocotrienol, Tissue-Specific Promoter

\section{INTRODUCTION}

Vitamin E refers to four isomers $(\alpha, \beta, \gamma$ and $\delta$ ) each of tocopherol and tocotrienol produced by the shikimate and non-mevalonate pathways (Fig. 1). Both the $\alpha$ tocopherol and $\alpha$-tocotrienol have high antioxidant properties and play an important role in influencing the biological activities in human beings (Traber and Atkinson, 2007). In addition, it has been reported that the $\alpha$-tocotrienol has several beneficial effects on human health better than the $\alpha$-tocopherol due to the shorter and thicker prenyl tail that makes the molecule more flexible

Corresponding Author: Siti Nor Akmar Abdullah, Department of Agriculture Technology, Faculty of Agriculture, University Putra Malaysia, 43400 UPM Serdang, Selangor Darul Ehsan, Malaysia 
to penetrate the cell membranes. This results in superior biological activities that help to promote cellular growth (Nesaretnam et al., 1995) and support the body's innate neuroprotective characteristics (Sanagi et al., 2006; Ryynanen et al., 2004).

Plants widely differ in their vitamin E isomers level and no single plant provides the entire vitamin E family of isomers in nutritionally adequate amounts. Even within a plant, large variances exist in the proportions of the $\alpha, \beta, \gamma$ and $\delta$ isomers. Typically, green vegetables have high level of tocopherol and certain plant seeds contain high level of tocotrienol (Ajjawi and Shintani, 2004; Abbasi et al., 2007). Therefore, plants that have been metabolically engineered to produce both compounds in vegetative tissues are attractive sources for both the tocopherol and tocotrienol.

Tocopherol Cyclase (TC) adds a second ring at the junction between the aromatic head group and the prenyl tail to create a two-ring structure which is known as chromanol ring in the tocopherol biosynthesis (Ajjawi and Shintani, 2004). Subsequent methylation of MPBQ methyltransferase and $\gamma$-tocopherol methyltransferase poduce $\beta$ and $\alpha$-tocochromanols. Metabolite engineering to modify vitamin $\mathrm{E}$ content and composition had been carried out in potato with TC gene (Hofius et al., 2004). In addition, genetic engineering and pathway modification through suppression was applied in petunia with CHS gene (Napoli et al., 1990), tobacco with AtFAD7 gene (Oka et al., 2010) and in tomato with GA 20-oxidase1 gene (Olimpieri et al., 2011). The above investigations have concluded that when one of the metabolite present in the biosynthesis pathway is suppressed, the other pathway that exists will be initiated to synthesize other forms of metabolites that are necessary for the survival of the plants.

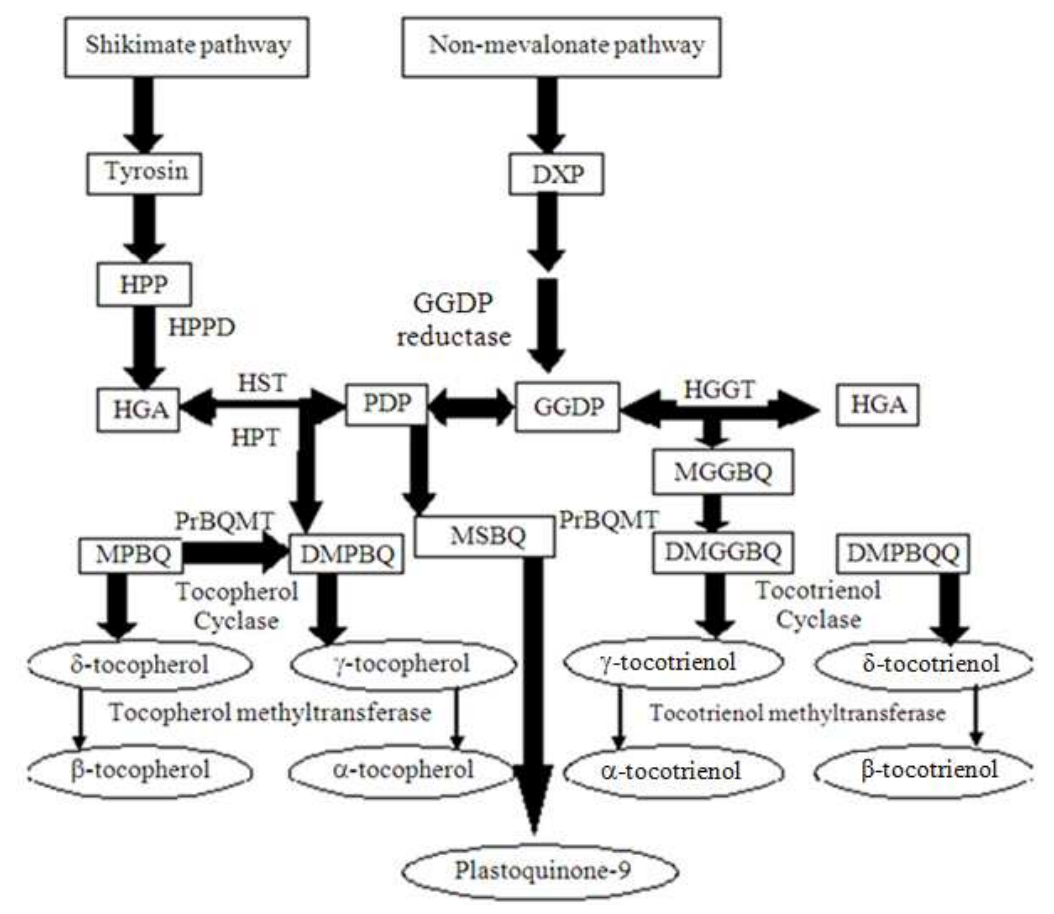

Fig. 1. The tocochromanols and plastoquinone biosynthethis pathway in plants. It represents the enzymatic reactions and the intermediate products that are involved. Shikimate and non-mevalonate pathway takes place in the plastid and the formed metabolites are transported to other part of the plant. Homogentisate Acid (HGA) and Phytyldiphosphate (PDP), derived from cytosolic aromatic amino acid metabolism and plastidic Deoxyxylulose 5-Phosphate Pathway (DXP), respectively serve as substrates for the synthesis of tocochromanol. Reactions between HGA and PDP or HGA with GGDP carry out by Homogentisate Phytyltransferase (HPT) or Homogentisate Geranylgeranyltransferase (HGGT) will produce tocochromanol. The intermediate products 2-Methyl-6-Phytyl-Benzoquinol (DMPBQ) and 2-Methyl-6-Geranylgeranyl-Benzoquinol (MGGBQ) will be further cyclased and methylated to produce $\alpha$-tocochromanol. Homogentisate Solanesyltransferase (HST) catalyzes the prenylation and decarboxylation of HGA to form 2-Methyl-6-Solanesyl-1,4-Benzoquinol (MSBQ). Enzymes in BOLD and UPPER CASE are specific to the synthesis of the subsequent intermediate products 
Partial conserved cDNA that encodes the open reading frame of TC gene was isolated and was expressed with Ubiquitin Promoter from maize (Ubi1P) or leaf-specific promoter from oil palm (LHCB) using the pDRB6b expression vector. Since most of the agricultural crops are not amenable to stable genetic transformation, agro-infiltration based system was used as a tool for transferring the transformed Agrobacterium with the foreign gene directly into the intact leaf tissues of Amaranthus sp. and Allium porrum. Suppression level of $\alpha$-tocopherol as well as the formation of $\alpha$-tocotrienol was successfully studied using these two different plant promoters. The aim of the present study is to induce the production of $\alpha$-tocotrienol in leaves tissue that do not contain of $\alpha$-tocotrienol by the co-suppression of TC.

\section{MATERIALS AND METHODS}

\subsection{Gene Constructs}

Recombinant vector constructs for transient gene expression and the control vectors were prepared according to the standard procedures (Sambrook et al., 1989). The PCR and DNA sequencing primers used in this study are shown in Table $\mathbf{1}$ and the bacterial strains and the plasmids are listed in Table 2. The competent cells of $E$. coli DH5 $\alpha$ were purchased from Yeastern Biotech Co., Ltd, Shijr Taipei, Taiwan. The pDRB6b vector digested with HindIII/KpnI, served as the backbone vector for $\mathrm{p} 4 \mathrm{a} 11$ and $\mathrm{p} 4 \mathrm{c} 9$. Ubiquitin promoter was isolated by using HindIII/BglII restriction enzyme from the pDRB8 vector while the LHCB was isolated by amplifying the sequences using FLHCB and RLHCB primers from the pGWLSO1 vector with the similar restriction site. The pDRB8 vector was also digested to isolate the NosT using HindIII/KpnI. Tocopherol Cyclase gene (TC) was amplified with FtcB2/RtcH2 primers from yT\&A-TC plasmid to produce $B g l \mathrm{II} /$ HindIII ends. The following amplification program was used: Heating at $95^{\circ} \mathrm{C}$ for 5 min for initial denaturation; 35 cycles using a Biometra ${ }^{\circledR}$ Tpersonal Thermocyler (Goettingen, Germany) at $94^{\circ} \mathrm{C}$ for $30 \mathrm{~s}$ for a second denaturation process, annealing temperature was optimised at $4^{\circ} \mathrm{C}$ lesser than its melting temperature; $72^{\circ} \mathrm{C}$ at $45 \mathrm{~s}$ for DNA extension; $72^{\circ} \mathrm{C}$ at $5 \mathrm{~min}$ for final DNA extension and stored at $4^{\circ} \mathrm{C}$. The $\mathrm{TC}$ gene was ligated to Ubi1P having $B g l I I$ restriction sites at $3{ }^{\prime}$ end to NosT having HindIII restriction sites at its 5 end. The resultant plasmid was named p4a11 (Fig. 2a). For p4c9 (Fig. 2b), the LHCB was ligated to TC gene and with NosT fragment having similar restriction sites as in p4a11.

The isolated recombinant vector constructs were linearised using single enzyme digestion according to the manufacturer's recommendations. The sizes of the produce vector constructs were compared with the control vectors. The successfully produced constructs were further confirmed by amplifying the TC gene with primary and nested primers (vcFTC, vcRTC, npfTC) that were flanked by Ubi1P or LHCB and NosT fragment between LB and RB2 border. The amplified PCR product was sequenced and analysed using the NCBI Blast.

\subsection{Selection and Growth of Transformed Bacteria}

E. coli $\mathrm{DH} 5 \alpha$ was grown for $16 \mathrm{~h}$ at $37^{\circ} \mathrm{C}$ (Sadre et al., 2006). Agrobacterium strains (AGL1) was obtained from Dr N.M. Upadhyaya, CSIRO, Australia. The AGL1 carrying the plasmid (pDRB6b, pDRB5b, p4a11 and p4c9) was streaked on LB agar (Merck, Darmstadt, Germany) plates containing spectinomycin (Calbiochem ${ }^{\circledR}$ Germany) and rifampicin (Calbiochem ${ }^{\circledR}$ Canada). The plates were incubated at $28^{\circ} \mathrm{C}$ for two days. The AGL1 was inoculated in $5 \mathrm{~mL}$ LB broth with the same antibiotics and was grown overnight at $28^{\circ} \mathrm{C}$ on a shaker at $150 \mathrm{rpm}$ (Lee and Yang, 2006). All the transformed bacterial strains were grown on LuriaBertani (LB) agar or broth (Difco ${ }^{\mathrm{TM}}$, USA). Broth culture(s) were grown with shaking at $200 \mathrm{rpm}$.

\subsection{Agro-Infiltration of Vegetable Leaves}

This section was performed as described by Lee and Yang (2006) with only slight modification. Two milliliter of culture was collected in a sterile microcentrifuge by centrifugation at $8000 \mathrm{rpm}$ for 10 min. The Agrobacteria pellet was resuspended in $1 \mathrm{~mL}$ sterilised induction medium $\left(10.5 \mathrm{~g} \mathrm{~L}^{-1} \mathrm{~K}_{2} \mathrm{HPO}_{4}, 4.5 \mathrm{~g}\right.$ $\mathrm{L}^{-1} \mathrm{KH}_{2} \mathrm{PO}_{4}, 1 \mathrm{~g} \mathrm{~L}^{-1}\left(\mathrm{NH}_{4}\right)_{2} \mathrm{SO}_{4}, 0.5 \mathrm{~g} \mathrm{~L}^{-1}$ NaCitrate, $1 \mathrm{~g}$ $\mathrm{L}^{-1}$ glucose, $1 \mathrm{~g} \mathrm{~L}^{-1}$ fructose, $4 \mathrm{~g} \mathrm{~L}^{-1}$ glycerol, $1 \mathrm{mM}$ MgSO4, 10 mM MES, pH 5.6).

Four milliliter of sterilised infiltration medium (10 $\mathrm{mM} \mathrm{MgSO}_{4}, 10 \mathrm{mM}$ MES, $\mathrm{pH}$ 5.6) was added to make up $5 \mathrm{~mL}$ of medium supplemented with $100 \mu \mathrm{M}$ acetosyringone (Sigma Aldrich ${ }^{\circledR}$ Chemistry, USA) and $50 \mathrm{mg} \mathrm{L} \mathrm{L}^{-1}$ of spectinomycin. The Agrobacteria suspension was further grown at $28^{\circ} \mathrm{C}$ for $6 \mathrm{~h}$. The bacterial cultures were collected by centrifugation and were resuspended in infiltration medium containing 200 $\mu \mathrm{M}$ acetosyringone to 1.0 OD at $600 \mathrm{~nm}$. 
Table 1. PCR and DNA sequencing primers used in this study

\begin{tabular}{llll}
\hline Primer name & $\mathrm{T}_{\mathrm{m}}{ }^{\circ} \mathrm{C}$ & Nucleotide sequence $5{ }^{`}$ to $3^{`}$ & Template \\
\hline FtcB2 & 61.7 & TTAATAAGATCTAGGTCGAAGTATGTCC & yT\&A-TC \\
RtcH2 & 59.0 & AATAAATTAAAGCTTTTTCCCACAATTGC & yT\&A-TC \\
vcFTC & 66.5 & ACAGCAGGCTGGCTTGCAGC & p4a11, p4c9 \\
vcRTC & 66.5 & TTGTTGGAGCCCGCAAGGGG & p4a11, p4c9 \\
npfTC & 64.5 & TGCATGGCAGCTGGCTTGTCA & p4a11, p4c9 \\
FLHCB & 63.1 & AGGGGGAAGCTTAAATAAAAAGATCGG & pGWLSO1 \\
RLHCB & 63.1 & TTCAAT $A$ AGATCTGATGCCTTGGAG & pGWLSO1 \\
\hline
\end{tabular}

*Sequence in italics underlined represents restriction enzyme sites

Table 2. Bacterial strains and plasmids used in this study.

\begin{tabular}{|c|c|c|}
\hline & Genotype/relevant properties & Source/reference \\
\hline \multicolumn{3}{|l|}{ Strains } \\
\hline Escherichia coli $\mathrm{DH} 5 \alpha$ & $\begin{array}{l}\left.\text { endA1 recA1 relA1 gyrA96 hsdR17( } \mathrm{r}_{\mathrm{k}}{ }^{-}, \mathrm{m}_{\mathrm{k}}{ }^{+}\right) \text {phoA } \\
\text { supE44 thi-1 } \Delta(\mathrm{lacZYA}-\operatorname{argF}) \mathrm{U} 169 \Phi 80 \Delta(\mathrm{lacZ}) \mathrm{M} 15 \mathrm{~F}-\end{array}$ & Yeastern Biotech Co., \\
\hline $\begin{array}{l}\text { Agrobacterium tumefaciens } \\
\text { (AGL1) }\end{array}$ & Broad host range strain for plant transformation, Rif $^{\mathrm{R}}$ & CSIRO Plant Industry \\
\hline \multicolumn{3}{|l|}{ Plasmids } \\
\hline pDRB5b & a donor of Ubi1-intron, uidA, linearised with $K p n \mathrm{I}$ & CSIRO Plant Industry \\
\hline pDRB $6 b$ & An expression vector, $\mathrm{Spec}^{\mathrm{R}}$, linearised with $K p n \mathrm{I}$ & CSIRO Plant Industry \\
\hline pDRB8 & a donor of Ubi1P and NosT, linearised with SmaI & CSIRO Plant Industry \\
\hline pGWLSO1 & a donor of leaf specific promoter (LHCB) & MPOB \\
\hline yT\&A & cloning vector, $\mathrm{Amp}^{\mathrm{R}}$ & Yeastern Biotech Co., \\
\hline yT\&A-TC & recombinant vector, a donor of TC gene & This study \\
\hline p4a11 & $\begin{array}{l}\text { recombinant vector, T-DNA region consist of Ubi1P, } \\
\text { TC, NosT, } \operatorname{Spec}^{\mathrm{R}} \text {, linearised with Not } \mathrm{I}\end{array}$ & This study \\
\hline $\mathrm{p} 4 \mathrm{c} 9$ & 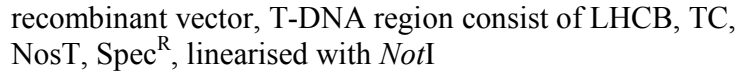 & This study \\
\hline
\end{tabular}

\begin{tabular}{|c|c|c|c|c|}
\hline a.p4a11 & HindIII & BglII & HindIII & $K p n \mathrm{I}$ \\
\hline $\mathrm{RB} 2$ & Ubil P & TC & NosT & L LB \\
\hline b.p4c9 & HindIII & $B g / I I$ & HindIII & $K p n I$ \\
\hline RB2 & LHCB & TC & NosT & L LB \\
\hline
\end{tabular}

Fig. 2. Chimeric recombinant vector constructs with Tocopherol Cyclase gene (TC). RB2: Second right border, LB: Left Border. Gene constructs for transient gene expression were prepared by fusing together partial sense sequences for TC (622 bp) with maize ubiquitin promoter-Ubi1P (950 bp) or leaf-specific promoter-LHCB (1000 bp), NosT indicates the nos terminator (503 bp). The restriction enzyme sites in italics were used for ligations. The length of (a) p4a11 2075 bp and (b) p4c9 2125 bp

Agroinfiltration was conducted by infiltration of the Agrobacteria suspension into exposed intercellular of the leaves that are still attached to the intact plant. For each recombinant vector construct and control, three plants pot $^{-1}$ of Amaranthus sp. and Allium porrum were grown.
In order to have optimum plant growth, Amaranthus sp. was grown for up to one month while Allium porrum was grown for up to four month. Both crops were irrigated twice in a day at 0800 and 1600 . All healthy leaves were chosen for infiltration. The injured leaves were 
submerged with the suspension for $1 \mathrm{~min}$. After infiltration the leaves were covered overnight to maintain the humidity prior to transferring back to the glasshouse. Three leaves samples were harvested from each plant at each day three, five and seven. Harvested samples were freeze dried and were stored at $-80^{\circ} \mathrm{C}$ prior to analysis.

\subsection{Evaluation of Transient Expression}

The GUS staining was performed as previously described (Jefferson, 1987). To compare the transient expression of LHCB with Ubi1P, pieces of leaves from Amaranthus sp./Allium porrum that was infiltrated with pDRB5b were assayed for GUS analysis to determine the basis for selecting the developmental timing of the mRNA expression of GUS driven by UbilP and to measure the extent of the transgene expression in transient systems. The infiltrated leaves were soaked in the GUS staining solution ( $5 \mathrm{mg}$ of $\mathrm{X}$ Gluc in $0.1 \mathrm{~mL}$ of $N, N$-dimethylformamide in $10 \mathrm{~mL}$ of buffer containing $50 \mathrm{mM}$ phosphate buffer, $15 \mathrm{mM}$ EDTA, $0.01 \%$ Tween-20 pH 7.0). They were incubated for $16 \mathrm{~h}$ at $37^{\circ} \mathrm{C}$. The stained leaf tissues were rinsed with $70 \%$ ethanol until complete decoloration. The pieces of plant leaves infiltrated with pDRB6b (empty vector) served as control plant.

\subsection{Data Analysis}

All experiments were repeated thrice with at least three replicates for each analysis. The data presented herein are the average results of the experiments and all data were subjected to normality test. One-way Analysis of Variance (ANOVA) was performed for all the raw data using Duncan multiple range tests. All analyses were performed at the level of $5.0 \%$ using SPSS 17.0 software package (SPSS Inc., IL, USA).

\section{RESULTS}

\subsection{Recombinant Vector Analysis}

The isolated DNA fragments having heterologous ends were successfully inserted in between the RB2-LB of the pDRB6b vector. Our recombinant vector constructs for transient gene expression, p4a11 and p4c9 were designed to contain the partial conserved cDNA sequence of Tocopherol Cyclase gene (TC) from Elaeis guineensis. They were controlled by UbilP and LHCB, respectively and NosT as the termination sites. All the digested recombinant vector constructs successfully produced the DNA fragments of the expected band size. The PCR product which was sequenced and subjected to nucleotide blast, shared $98 \%$ identity with TC from Elaeis oleifera (EU057618.1), 79\% Vitis vinifera (XM002281388.2), 76\% Glycine max (XM003522656.1) and Gossypium hirsutum (DQ456881.1), 77\% to Ricinus communis (XM002516502.1) and Eucalyptus gunnii (AY336944.1).

\subsection{Evaluation of Transient Expression}

Reporter gene (GUS) was used to assay for the activity of a particular promoter in a cell or organism. The expression of GUS driven by Ubi1P in pDRB5b showed by the blue staining was visible at day three, five and seven on the leaf of Amaranthus sp. while in Allium porrum at day five and seven (Fig. 3a, b). The results showed that the Ubi1P starts the expression on day three till day seven for Amaranthus sp. but on day five till seven for Allium porrum. Therefore, this timing data could be used to compare with the expression pattern of LHCB and Ubil promoter. However, this result will not elucidate the level of $\alpha$-tocopherol suppression and $\alpha$-tocotrienol induction.

\subsection{Co-suppression Profile of $\alpha$-Tocopherol}

The HPLC assay was used to determine the concentration of $\alpha$-tocopherol and $\alpha$-tocotrienol in the experimental leaves. The retention times were confirmed using standard compounds of $\alpha$-tocopherol and $\alpha$ tocotrienol. The results of HPLC analysis are shown in Table 3. The Amaranthus sp. leaves infiltrated with p4a11 showed significantly reduced concentration $(\mathrm{p} \leq 0.05)$ of $\alpha$ tocopherol and that infiltrated with $\mathrm{p} 4 \mathrm{c} 9$ also showed lesser concentration of $\alpha$-tocopherol when compared with the control on all the tested days. In the Allium porrum infiltrated with $\mathrm{p} 4 \mathrm{a} 11$, significant reduction in $\alpha$ tocopherol was observed on day seven only. This was tally with the result obtained for GUS analysis. The other tested days showed insignificant reduction when compared with that of the control. In addition, in the Allium porrum infiltrated with $\mathrm{p} 4 \mathrm{c} 9$ showed significant losses on day three and seven while insignificant losses were detected on day five compared to the control. Interestingly, in all the extracts with suppressed $\alpha$ tocopherol production a peak corresponding to $\alpha$ tocotrienol was detected on the HPLC chromatogram (data not shown). It could be seen from Table 3 that a significant induced production of $\alpha$-tocotrienol was detected in both Amaranthus sp. and Allium porrum. 
(a)

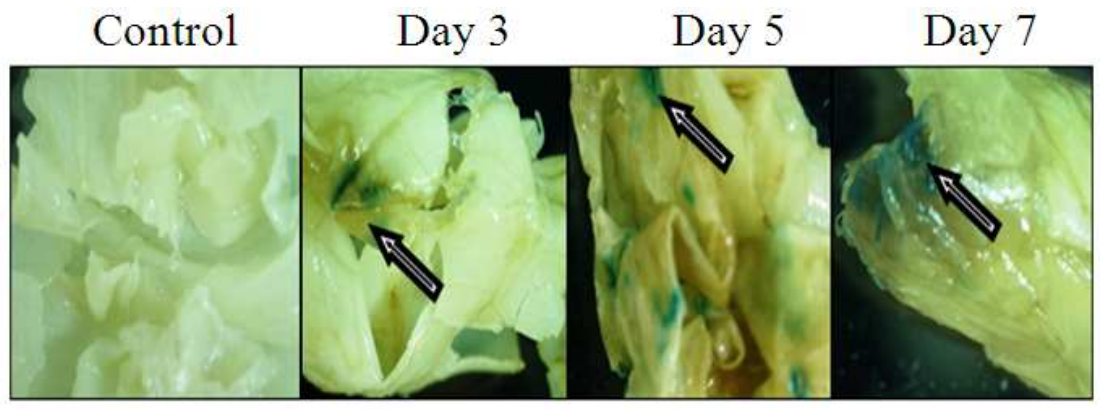

(b)

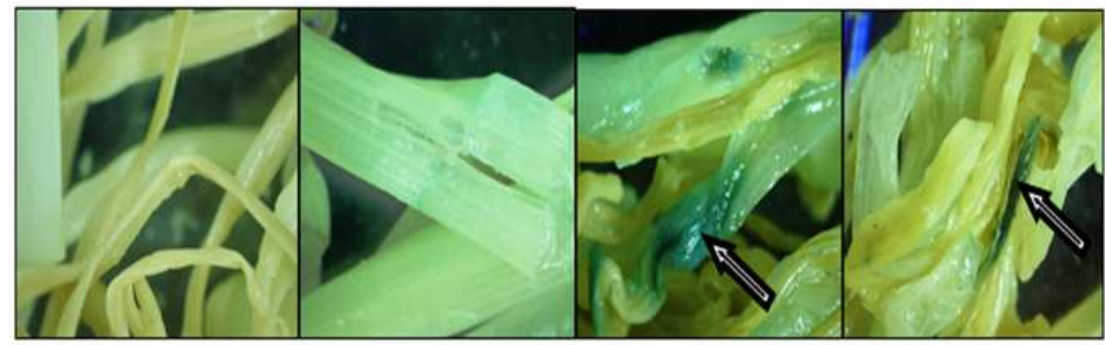

Fig. 3. Histochemical GUS staining. The infiltrated plant leaves with pDRB5b vector were incubated at $37^{\circ} \mathrm{C}$ for $16 \mathrm{~h}$. The expression of GUS driven by UbilP showed by the blue staining (arrow) was highly visible only at day three, five and seven for (a) Amaranthus sp. and low visibility on day three and high visibility on day five and seven for (b) Allium porrum

Table 3. Summary of the HPLC data on $\alpha$-tocochromanol concentration and percentage of $\alpha$-tocopherol suppression after transient transformation by $\mathrm{p} 4 \mathrm{a} 11$ and $\mathrm{p} 4 \mathrm{c} 9$ compared to control pDRB6b on day three, five and seven

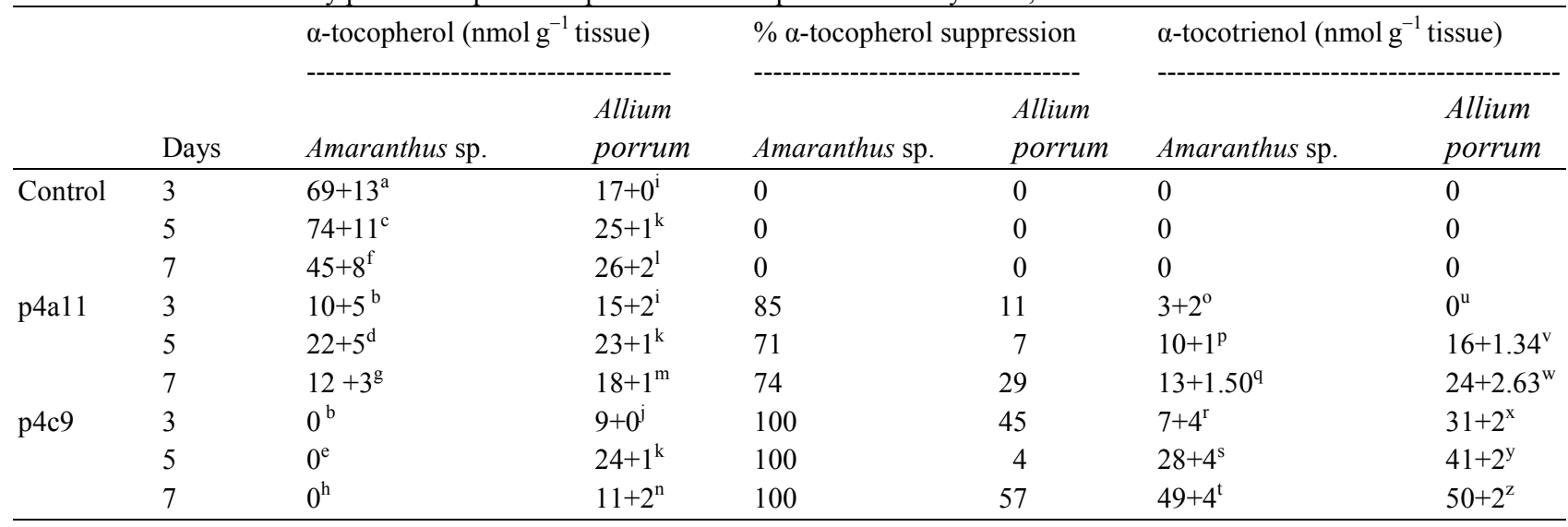

The data shown are expressed as mean of three replicates + SE from three representative experiments. SE indicates standard error bar. Same letter denotes as being not significant ( $\mathrm{p} \geq 0.05)$ by Duncun test

\section{DISCUSSION}

The present studies revealed an interesting observation that the $\alpha$-tocopherol suppression level is higher in Amaranthus sp. when compared with that of Allium porrum. This is due to the ability of LHCB (tissue specific promoter) to accumulate large amounts of the aberrant mRNA of TC than that of Ubi1P (constitutive promoter) that led to higher level of $\alpha$-tocopherol suppression in Amaranthus sp. when compared to the Allium porrum. Many studies have suggested that the transgene expression controlled by 
a tissue-specific promoter worked more effectively in the specific tissue compared to a constitutive promoter (Jones and Sparks, 2009; Schillberg et al., 2005; Masani Abdul et al., 2009). It also appears to be inconsistent with previous reports where Ubi1P was often used to drive the expression of genes in monocotyledons.

The above discussions confirm that the LHCB had driven more effective expression of TC aberrant mRNA than Ubi1P. Similar observation has been reported by Porfirova et al. (2002) who have confirmed that the reduction in TC activity due to gene silencing will result in the loss of $\alpha$-tocopherol. Besides the usage of the promoters, the cause of the different levels of suppression in Amaranthus sp. and Allium porrum could be due to the different types of photosynthetic pathways in them. Amaranthus sp. uses $\mathrm{C}_{4}$ photosynthetic pathway while Allium porrum uses $\mathrm{C}_{3}$ photosynthetic pathway. The two photosynthetic pathways show significantly different level of gene expression. The Amaranthus sp. which is a $\mathrm{C}_{4}$ plant has reduced state on the shikimate pathway and hence capable of suppressing $\alpha$-tocopherol easily than $\mathrm{C}_{3}$ plant (Gowik and Westhoff, 2011). This finding was however different from that reported by Hofius et al. (2004) where TC silencing causes severe suppression in $\alpha$-tocopherol was detected in $\mathrm{C}_{3}$ plant.

The p4a11 and $\mathrm{p} 4 \mathrm{c} 9$ recombinant vector constructs containing partial conserved cDNA of TC gene sequence spanning from nucleotide 45-665 of the ortologous cDNA of EU057618 (Fig. 4) showed over 75\% identity with TC of other plant species. This construct enabled the introduction of partial cDNA of the TC to produce the aberrant mRNAs similar to endogenous TC but with distinct lifetime (stabilities). The limited lifetime of aberrant mRNA enables the cell to alter the protein synthesis rapidly in response to its changing needs that lead to the destruction of an mRNA as mRNA lifetimes ranging from several minutes to days. The lesser the stability of a mRNA the lesser the protein will be produced from the particular mRNA. Further investigation of the phenomenon in plants indicated that the down regulation was due to the PostTranscriptional Gene Silencing (PTGS) of a particular gene due to the presence of a related aberrant gene expression via an increased rate of mRNA degradation (Oka et al., 2010). Therefore, the PTGS mechanism had degraded the population of less stable TC mRNAs and led to successful suppression of $\alpha$-tocopherol as the transgene contained higher homology to the cellular TC gene of the endogenous copy which will be degraded too. This shows that the introduced TC gene is sufficient for suppression of endogenous TC transcript level. This phenomenon was also called cosuppression of gene expression or gene silencing (Cameron and Jennings, 1991). According to a study that was previously reported (Abbasi et al., 2007), total blockage of $\alpha$-tocopherol was achieved through silencing of $\gamma$-TMT. But in this study, similar blockage as reported by Porfirova et al. (2002) was noticed by silencing TC gene in Amaranthus sp. infiltrated with $\mathrm{p} 4 \mathrm{c} 9$.

The breakthrough in this study was achieved when the production of $\alpha$-tocotrienol in infiltrated Amaranthus sp./Allium porrum was detected parallelly with $\alpha$-tocopherol suppression and the observation was similar to that reported by Asensi-Fabado and Munne-Bosch (2010). Furthermore, $\alpha$-tocotrienol production appeared not to be entirely dependent on the level of $\alpha$-tocopherol suppression as $\alpha$-tocotrienol produced more in plants infiltrated with p4a11 than $\mathrm{p} 4 \mathrm{c}$, even though higher suppression of $\alpha$-tocopherol was detected in $\mathrm{p} 4 \mathrm{c} 9$. In addition, $\alpha$-tocotrienol production was observed in Allium porrum higher than in Amaranthus sp. even though high suppression was detected in Amaranthus sp. In addition, it has been reported that plants which do not accumulate $\alpha$ tocotrienol may not have a tocotrienol-specific prenyltransferase (HGGT) (Falk and Munne-Bosch, 2010). But, the present study raises an interesting point as to how the silencing of TC could lead to the induction of $\alpha$-tocotrienol. There are many supporting publications to answer this question. The suppression of $\alpha$-tocopherol appeared to be sufficient to shift the metabolic pathway towards producing $\alpha$-tocotrienol as an alternative antioxidant in both plants (Abbasi et al., 2007). Therefore, we are suggesting that the $\alpha$ tocotrienol production was observed in Amaranthus sp. and Allium porrum due to the natural ability of the plant to adopt for its survival in $\alpha$-tocopherol deficient condition after transgenic manipulation of the biosynthetic pathway (Falk and Munne-Bosch, 2010). These cases demonstrate that plants appeared to be flexible in adapting themselves by altering different genes in different ways for survivability. 

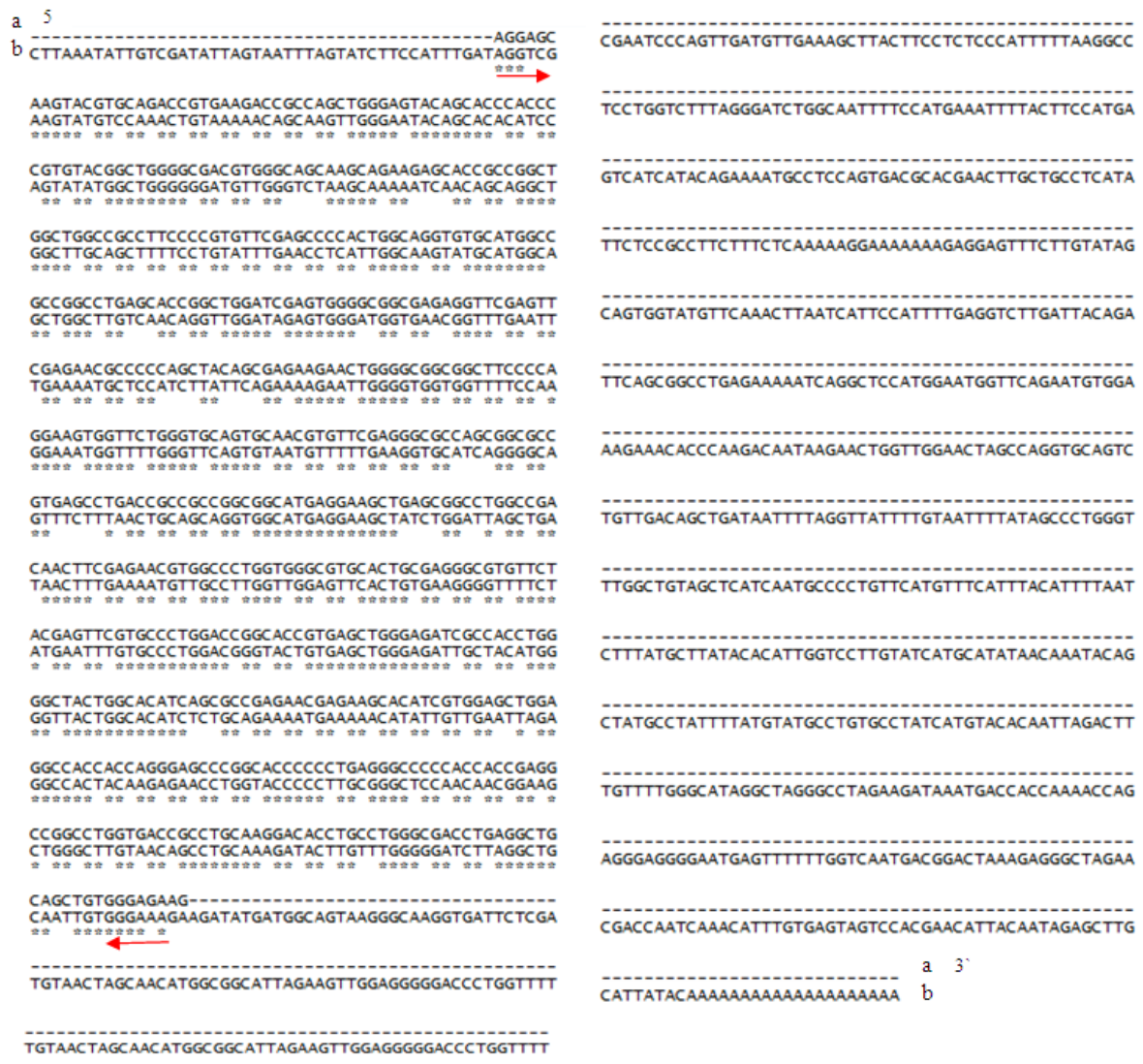

CTATGCCTATTTTATGTATGCCTGTGCCTATCATGTACACAATTAGACTT

TGITTGGGCATAGGCTAGGGCCTAGAAGATAAATGACCACCAAAACCAG

AGGGAGGGGATGAGTIIITGGTCAATGACGGACTAAAGAGGGCTAGAA

CGACCAATCAAACATTTGTGGTAGTCCACGAACATTACAATAGAGCTTG a 3

CATTATACAAAAAAAAAAAAAAAAAAA

Fig. 4. Partial conserved cDNA of TC gene sequences (1528 bp) spanning from nucleotide 45-665 of the ortologous cDNA of EU057618 (shown by red arrow). (a): Isolated gene sequence from Elaeis guineensis; (b): Gene sequence from Elaeis oleifera clone EoEST-835 TC (EU057618)

Secondly, the result also showed that due to the active and stable characteristics of TC enzyme (Collakova and Della Penna 2001) it is not totally silenced and hence the remaining TC mRNAs are capable of producing a fair amount of $\alpha$-tocopherol. Therefore, $\alpha$-tocopherol still can be detected in the plants infiltrated with p4a11. Thirdly, the presence of $\alpha$ tocotrienol in both plants might be due to the involvement of more than a single gene that is able to function as TC enzyme. For example, Homogentisate Solanesyltransferase (HST) is a gene expressed in the leaves required for the biosynthesis of plastoquinones which catalyses the condensation of Solanesyl 2P (SDP) and HGA, accepts farnesyl $2 \mathrm{P}$ and geranylgeranyl $2 \mathrm{P}$ as prenyl donors for $\alpha$-tocotrienol production, thus providing further evidence in support of $\alpha$-tocotrienol production in the absence of a specific HGGT.

In addition, the enhanced supply of HGA may affect the substrate specificity of prenyltransferases leaking towards $\alpha$-tocotrienol synthesis. In such plants, $\alpha$ tocotrienol can accumulate in the leaves (Sadre et al., 2006; Venkatesh et al., 2006). This showed further evidence that HGGT may have no influence but other factors such as composition of plastidic pools of HGA, GGDP and PDP might have influence in the production of $\alpha$-tocotrienol (Karunanandaa et al., 2005). Besides that, presence of of sucrose export defectivel gene that is capable of encoding enzyme with the same function as TC (Porfirova et al., 2002) could also be the reason of $\alpha$ tocotrienol production. Interestingly, this gene represents orthologous single copy gene of TC and which may be capable of producing $\alpha$-tocotrienol (Hofius et al., 2004).

\section{CONCLUSION}

We have successfully demonstrated the suppression of $\alpha$-tocopherol level and induction of $\alpha$-tocotrienol biosynthesis in Amaranthus sp. and Allium porrum by 
silencing gene expression of the Tocopherol/Tocotrienol Cyclase (TC). The level of $\alpha$-tocochromanol within groups and between groups reported in this study was estimated based on the HPLC assay. The control plant which was infiltrated with pDRB6b vector (empty vector) was totally incapable of producing $\alpha$-tocotrienol, so the ability of the transiently transformed plant to produce $\alpha$-tocotrienol is biologically significant. We have developed the HPLC analytical method to correlate the gene expression to the level of metabolite detection. This was developed towards our objective of modifying the nutrient content ( $\alpha$-tocopherol and $\alpha$-tocotrienol) in the tested plants where the data on metabolite production was mainly required. The excellent results achieved in the present study have motivated us to advance towards the next level of producing stable tocotrienol-biofortified transformed valuable plants that could serve as the source of chemical antioxidants for industrial applications as well as in therapeutics.

\section{ACKNOWLEDGEMENT}

The authors would like to thank Dr N.M Upadhyaya from CSIRO Plant Industry for providing a series of pDRB vectors and $A$. tumefaciens (AGL1). The senior author would like to express appreciation to Universiti Malaya for providing financial assistance in the form of Skim Latihan Akademik IPTA scholarship.

\section{REFERENCES}

Abbasi, A.R., M. Hajirezaei, D. Hofius, U. Sonnewald and L.M. Voll, 2007. Specific roles of $\alpha$ and $\gamma$ tocopherol in abiotic stress responses of transgenic tobacco. Plant Physiol., 143: 1720-1738. DOI: 10.1104/pp106.094771

Ajjawi, I. and D. Shintani, 2004. Engineered plants with elevated vitamin E: A nutraceutical success story. Trends Biotechnol., 22: 104-107. DOI: 10.1016/j.tibtech.2004.01.008

Asensi-Fabado, M.A. and S. Munne-Bosch, 2010. Vitamins in plants: Occurrence, biosynthesis and antioxidant. Trends Plant Sci., 15: 582-592. DOI:0.1016/j.tplants.2010.07.003

Cameron, F.H. and P.A. Jennings, 1991. Inhibition of gene expression by a short sense fragment. Nucleic Acids Res., 19: 469-475. PMID: 2011521

Collakova, E. and D. Della Penna, 2001. Isolation and functional analysis of homogentisate phytyltransferase from Synechocystis sp. PCC 6803 and Arabidopsis. Plant Physiol., 127: 1113-1124. PMID: 11706191
Falk, F. and S. Munne-Bosch, 2010. Tocochromanol functions in plants: Antioxidation and beyond. J. Exp. Botany, 61: 1549-1566. PMID: 20385544

Gowik, U. and P. Westhoff, 2011. The path from $\mathrm{C}_{3}$ to $\mathrm{C}_{4}$ photosynthesis. Plant Physiol., 155: 56-63. DOI: 10.1104/pp.110

Hofius, D., M.R. Hajirezaei, M. Geiger, H. Tschiersch and M. Melzer et al., 2004. RNAi-mediated tocopherol deficiency impairs photoassimilate export in transgenic potato plants. Plant Physiol., 135: 1256-1268. DOI: 10.1104/pp.104.043927

Jefferson, R.A., 1987. Assaying chimeric genes in plants: The GUS gene fusion system. Plant Molecular Biol. Rep., 5: 387-405. DOI: 10.1007/BF02667740

Jones, H.D. and C.A. Sparks, 2009. Promoter sequences for defining transgene expression. Methods Molecular Biol., 478: 171-184. PMID: 19009446

Karunanandaa, B., Q. Qi, M. Hao, S.R. Basziz and P.K. Jensen et al., 2005. Metabolically engineered oilseed crops with enhanced seed tocopherol. Metabolic Eng. PMID: 16125431

Lee, M.W. and Y. Yang, 2006. Transient expression assay by agroinfiltration of leaves. Methods Molecular Biol., 9: 223-225. PMID: 16739580

Sanagi, M.M., A.A. Naim, A. Hussain, S.H. Siregar and M.S. Sarjadi et al., 2006. Development and Application of New Modified Poly (styrenedivinylbenzene) Adsorbents and Chromatography Stationary Phases. 1st Edn., Universiti Teknologi Malaysia, Skudai, Johor, ISBN-10: 9673533229, pp: 113 .

Masani Abdul, M.Y., G.K. Ahmad Parveez, A.M. Dayang Izawati, C.P. Lan and A. Siti Nor Akmar, 2009. Construction of PHB and PHBV multiplegene vectors driven by an oil palm leaf-specific promoter. Plasmid, 62: 191-200. PMID: 19699761

Napoli. C., C. Lemieux and R. Jorgensen, 1990. Introduction of a chimeric chalcone synthase gene into Petunia results in reversible co-suppression of homologus genes in trans. Plant Cell, 2: 279-289. PMCID: 159885

Nesaretnam, K., N. Guthrie, A.F. Chambers and K.K. Carrol, 1995. Effects of tocotrienols on the growth of a human breast cancer cell line in culture. Lipids, 30: 1139-1143. PMID: 8614304

Oka, S.I., K. Midorikawa and H. Kodama, 2010. Co suppression and RNAi induced by Arabidopsis ortholog gene sequences in tobacco. Plant Biotechnol. Rep., 4: 185-192. DOI: 10.1007/s11816010-0135-2 
Olimpieri, I., R. Caccia, M.E. Picarella, A. Pucci and E. Santangelo et al., 2011. Constitutive co-suppression of the GA 20-oxidasel gene in tomato leads to severe defects in vegetative and reproductive development. Plant Sci., 180: 496-503. PMID: 21421397

Porfirova, S., E. Bergmuller, S. Tropf, R. Lemke and P. Dormann, 2002. Isolation of an Arabidopsis mutant lacking vitamin $\mathrm{E}$ and identification of a cyclise essential for all tocopherol biosynthesis. PNAS, 99: 12495-12500. PMID: 129473

Ryynanen, M., A.M. Lampi, P. Salo-Vaananen, V. Ollilainen and V. Piironen, 2004. A small scale sample preparation method with HPLC analysis for determination of tocopherols and tocotrienols in cereals. J. Food Compos. Analytical, 17: 749-765. DOI: 10.1016/j.jfca.2003.09.014

Sadre, R., J. Gruber and M. Frentzen, 2006. Characterization of homogentisate prenyltransferases involved in plastoquinone-9 and tocochromanol biosynthesis. FEBS Lett., 580: 53575362. PMID: 16989822
Sambrook, J., E.F. Fritsch and T. Maniatis, 1989. Molecular Cloning: A Laboratory Manual. 2nd Edn., Cold Spring Harbor Laboratory Press, ISBN-10: 0879693096, pp: 3.

Schillberg, S., R.M. Twyman and R. Fischer, 2005. Opportunities for recombinant antigen and antibody expression in transgenic plants-technology assessment. Vaccine, 23: 1764-1769. PMID: 15734038

Traber, M.G. and J. Atkinson, 2007. Vitamin E, antioxidant and nothing more. Free Radical Biol. Med., 43: 4-15. PMID: 17561088

Venkatesh, T.V., B. Karunanandaa, D.L. Free, J.M. Rottnek and S.R. Basziz et al., 2006 Identification and characterization of an Arabidopsis homogentisate phytyltransferase paralog. Planta, 223: 1134-1144. PMID: 16408209 